\title{
Mental health and human rights: challenges for a new millennium
}

\author{
Brendan D Kelly
}

Ir J Psych Med 2001; 18(4): 114-115

The World Health Organisation (WHO) devoted World Health Day 2001 to global advocacy on mental health issues. Societies were urged to focus on reducing the treatment gaps in mental health and ensuring the benefits of recent therapeutic advances reach all groups, particularly the underprivileged. Exclusion, stigma and the need for integrated care were also highlighted in an effort to encourage those in need to seek treatment.

The rights of the mentally ill are protected by the United Nations Principles for the Protection of Persons with Mental Illness (1991). There are, however, several problems with implementation. ${ }^{1}$ These principles do not have the status of a formal international treaty, and states are not required to use the principles to define minimum standards of care. Furthermore, the necessary changes in mental health care are not subject to inspection by an international body. Thus, inexpensive changes are more likely to be implemented than expensive ones, despite equal necessity for both. ${ }^{2}$ Concepts of 'mental health' and 'psychiatry' also vary between countries, which adds to the challenges faced by any set of principles intended for international application.

Renewed emphasis on human rights

The WHO's renewed emphasis on mental health and human rights is both necessary and timely. There are compelling social, political and legislative reasons to focus attention on the right to appropriate, acceptable mental health care at the present time.

In recent years, there has been a remarkable increase in the movement of asylum seekers across Europe, associated with significant post-migration stress, as well as previous trauma or mental illness. ${ }^{3}$ In Central America, there is substantial evidence of considerable difficulties with the delivery of effective mental health care. In Africa, Ethiopia has a population of 55 million and is served by one psychiatric hospital, and 11 psychiatrists.

In Asia, the World Psychiatric Association was recently called upon to investigate the human rights situation of political dissidents allegedly detained in psychiatric hospitals in the Peoples Republic of China. Indeed, the psychological sequelae of human rights abuse are reported to have reached epidemic proportions in several areas around the world. ${ }^{4}$

This is also a time of important legislative change. In the United Kingdom the white paper on Reforming the Mental Health $\mathrm{Act}^{5}$ continues to generate discussion and debate. The Human Rights Act 1998 came into effect in the UK in October 2000, incorporating articles of the European

Brendan D Kelly, MRCPsych, Stanley Research Fellow in Psychiatry, Stanley Research Foundation (Ireland), Cluain Mhuire Family Centre, Newtownpark Avenue, Blackrock, Co. Dublin, Ireland.

SUBMITTED: MARCH 30, 2001. ACCEPTED: AUGUST 5, 2001.
Convention of Human Rights into English law. This is intended to guarantee basic human rights in a variety of circumstances, and will have considerable impact on legal aspects of psychiatric practice. In Ireland, a new mental health act is at an advanced stage of preparation, and will also bring significant change to psychiatric practice. It is important that lawmaking is consistent with recent developments in the science and practice of psychiatry.

Advocacy, empowerment and guardianship

These social, political and legislative challenges are best met when mental health professionals and policy makers work in partnership with advocacy groups in advancing human rights. There is evidence that routine rights advocacy is less effective than advocacy based on patients needs and best interests. ${ }^{6}$ In this experimental model of advocacy, a personal advocate represents the needs and best interests of each individual patient from the time of admission until the time of discharge from involuntary care. This is associated with better compliance with aftercare and improves patients' and staff members' experience of involuntary hospitalisation.

Empowerment is an active process of enablement which increases a person's control over their own life, through the exercise of rights, the expression of opinion and various other means. The construct validity of the concept of empowerment has been endorsed ${ }^{7}$ and further research will clarify the ways in which client empowerment can help reduce discrimination and human rights abuse. Guardianship for the mentally ill is a related concept, with particular importance for protecting the rights of the severely mentally ill.

Certain groups present particular challenges. Advocacy has an especially important role in the delivery of mental health care to children and the learning disabled, including the increasing number of elderly learning disabled in need of psychiatric care.

Asylum-seekers too present particular challenges, as they come from a wide variety of cultural backgrounds and have sharply diminished community support. They may have already experienced human rights abuse, torture and displacement in their homeland. On arrival in a new country, they may well go on to face confinement in detention centres, enforced dispersal and ongoing discrimination. ${ }^{3}$ Clearly, the delivery of appropriate, acceptable mental health care to this population is a critical and complex task, requiring strategic planning and flexible resourcing. The roles of psychiatrists

It is entirely appropriate, then, that the WHO has chosen to renew its emphasis on mental health and human rights at this time. The continued provision of effective, evidence-based mental health care remains the central contribution that psychiatry can make toward the protection of human rights. Clearly, there is also a strong need for ongoing awareness and examination of issues related 
to consent, compulsion and the role of psychiatry in penal policy. These issues may vary considerably between countries, depending on local law and culture.

There are, however, three key areas in which psychiatry can help advance human rights in all jurisdictions: advocacy, training and education.

In the first instance, mental health professionals are well positioned to act as advocates for improved psychiatric care. They are only too familiar with the strengths and weaknesses of current models of care and existing legislation, and can advocate effectively both for better patient care and for appropriate working conditions for mental health professionals, right around the globe.

Secondly, it is important that psychiatric training recognises the relevance of human rights issues. The United Nations Principles for the Protection of Persons with Mental Illness (1991) could usefully inform medical education at undergraduate and postgraduate levels. Critical discussion of these principles ${ }^{1}$ could also be profitably incorporated into both undergraduate medical curricula and programmes of continuing professional development.

Finally, psychiatry is well positioned to provide appropriate education to colleagues, policy-makers and the public about mental health and human rights. The specific mental health needs of refugees, for example, represent one area in which mental health professionals do valuable work to highlight the unique psychological stressors and psychiatric needs of a specific population.

Medical, ethical and political challenges

Clearly, psychiatrists can only do a certain amount. Mental health care is always delivered in a particular social and political context, which may impact significantly on quality of care. In this sense, Rudolf Virchow was right: medicine is a social science, and politics its means of implementation. ${ }^{8}$ The mental health of refugees is intimately linked to their social and political situation in the host country. ${ }^{9}$ It is important to acknowledge the role of factors such as income and housing in their distress. ${ }^{10}$

The delivery of optimal mental health care requires adequate resourcing, appropriate training, and workable legislation. In many societies, these requirements present enormous challenges to policy-makers, governments and health-care workers. The challenges are at once medical and ethical, social and political. There is an urgent need to meet these challenges if we are to continue to build a mental health service that is equitable, acceptable, and most of all, effective.

\section{References}

1. Harding TW. Human rights law in the field of mental health: a critical review. Acta Psychiatrica Scandinavica Suppl 2000; 399: 24-30.

2. Goldman HH. Implementing the lessons of mental health service demonstrations: human rights issues. Acta Psychiatrica Scandinavica Supp $2000 ; 399: 51-4$.

3. Silove D, Steel Z, Watters C. Policies of deterrence and the mental health of asylum seekers. J American Medical Association 2000; 284: 604-11.

4. Chowdhury AN. Torture and Mental Health. Journal of the Indian Medical Association 2000; 98: 320-6.

5. Department of Health. Reforming the Mental Health Act. London: Stationery Office, 2000.

6. Rosenman S, Korten A, Newman L. Efficacy of continuing advocacy in involuntary treatment. Psychiatric Services 200; 51: 1029-33.

7. Corrigan PW, Faber D, Rashid F, Leary M. The construct validity of empowerment among consumers of mental health services. Schizophrenia Research 1999; 38: 77-84.

8. Macleod SM, McCullough HN. Social science education as a component of medical training. Social Science and Medicine 1994; 39: 1367-73.

9. Summerfield D. Asylum-seekers, refugees and mental health services in the UK. Psychiatric Bulletin 2001; 25: 161-2

10. Kahn RS, Wise PH, Kennedy BP, Kawachi I. State income inequality, household income, and maternal mental and physical health: cross sectional national survey. BMJ 200; 321: 1311-15.

\title{
AtTENTION ALl REgistrars AND TRAINEES!
}

\author{
Please notify us of any change of address so that we can ensure \\ the Journal gets to you.
}

New addresses should be sent to:

The Irish Journal of Psychological Medicine

\author{
25 Adelaide Street, \\ Dun Laoghaire, \\ Co Dublin, \\ Ireland.
}

or emailed to

psychological@medmedia.ie 


\section{too had a I f filled with , laughter ${ }_{\text {and }}$ tears.}

we made Wonderful

\section{Plans}

for our later years.

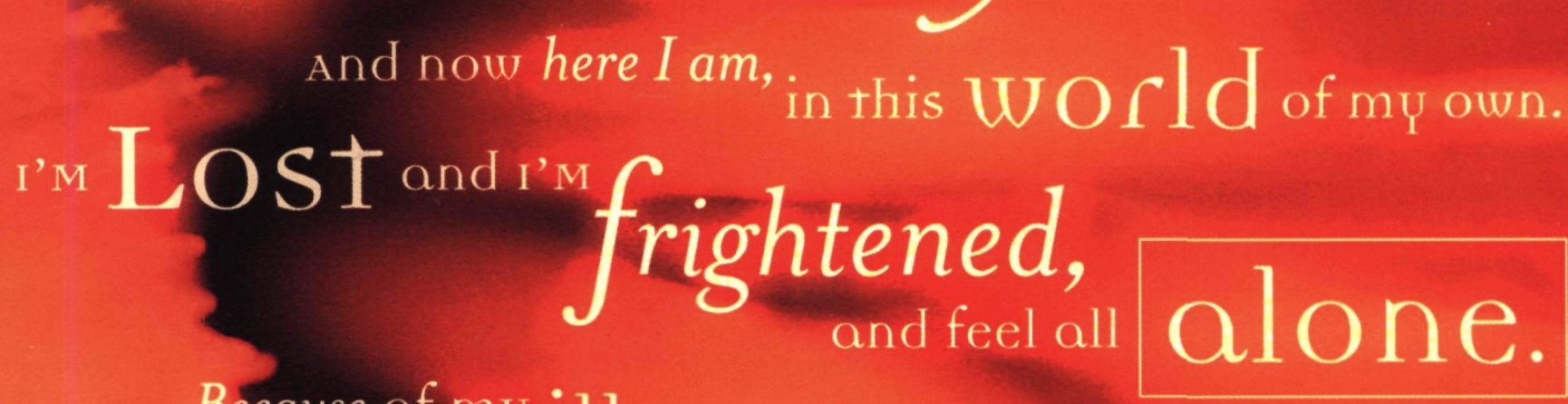

Because of mu illness,

I'm no longer the

same,

вuт reach оuт AND $_{\text {IOU }}$

I'm more than a name.

MORE THAN A NAME by Jerry Ham (Alzheimer's carer)

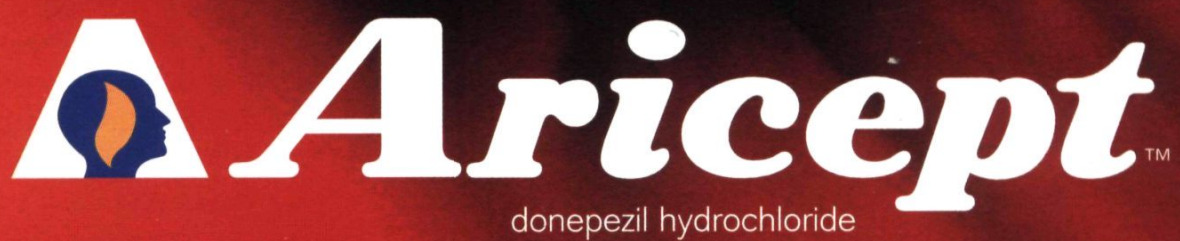

Making a difference in Alzheimer's

BED BRIEF PRESCRIBING INFORMATION

Afive
ARICEPT (donepezil hydrochloride)Please refer to the
SmPC before prescribing ARCEPT $5 \mathrm{mg}$ or ARICEPT
10mg. Indication: Symptomatic treatment of mild to moderately severe Alzheimer's dementia. Dose and
CNS administration: Adults/lelderly' 5 mo daily which may be oiscovere increased to $10 \mathrm{mp}$ once daily a trter at least one month. No dose adjustment necessary for patients with renal or mild-moderate hepatic impairment. Children; Not recommended. Contra-
Indications: Pregnancy. Hypersensitivity to donepezil, piperidine Indications: Pregnancy. Hypersensitivity to donepezil, piperidine
derivatives or any excipients used in ARICEPT. Laciation: Excretion into breast milk unknown. Women on donepezil should not breast
feed. Warnings and Precautions: Initiation and supervision by a leed. Warnings and Precautions: Initiation and supervision by a
ohysician with experience of Alzheimer's dementia. A caregiver should physician with experience of Alzheimer's dementia. A caregiver should of a therapeutic effect ceases Exacr discontinuation when evicence muscle relaxation Avoid congent use of anticholinestertype cholinergic agonists, cholinergic antagonists. Possibility of vaaotonic cholinergic agonists, cholinergic antagonists. Possibility of vagotonic
effect on the heart which may be particularly important with "sick

sinus syndrome", and supraventricular conduction conditions. There Syncope, bradycardia, and rare cases of sinoatrial block and have been reports of syncope and seizures - in such patients the atrioventricular block, and seizure have been reported. Rare reports of possibility of heart block or long sinusal pauses should be considered. liver dysfunction including hepatitis. Psychiatric disturbances, Carefur monitoring of patients at risk of ulcer disease including those including hallucinations, agitation and aggressive behaviour have also receiving NSAIDS. Cholinomimetics may cause bladder outflow been reported; these resolved on dose reduction or discontinuation. obstruction. Seizures occur in Alzheimer's disease and There have been some reports of anorexia, gastric and duodenal cholinomimetics have the potential to cause seizures. Cholinomimetics ulcers and gastrointestinal haemorrhage. Extrapyramidal symptoms ymptoms. Care in patients suffering asthma and obstructive Presentation: Blister packed in strips of 14. ARICEPT 5 mg; white, film pulmonary disease. As with all Alzheimer's patients, routine evaluation coated tablets marked 5 and ARICEPT, packs of 28. ARICEPT 10mg;

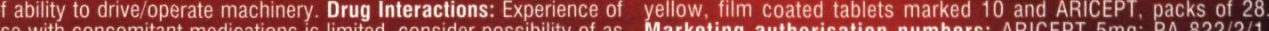

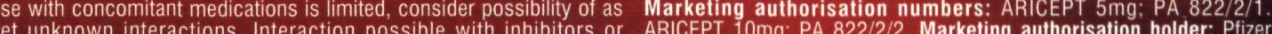

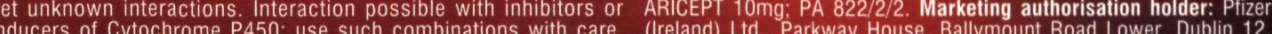

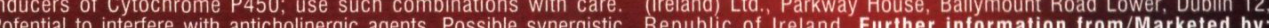
Penity with succiny

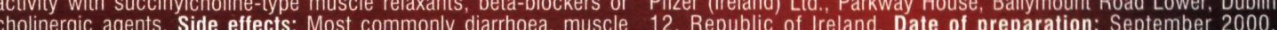

